\title{
Expression of the CD1a molecule in B- and T-lymphoproliferative skin conditions
}

\author{
BARBARA PIGOZZI, MATTEO BORDIGNON, ANNA BELLONI FORTINA, \\ GIORGIO MICHELOTTO and MAURO ALAIBAC
}

\author{
Unit of Dermatology, University of Padua, Via C. Battisti 206, I-35128 Padova, Italy
}

Received August 10, 2005; Accepted September 28, 2005

\begin{abstract}
The skin immune system is characterized by the presence of two types of CD1a expressing cells: Langerhans cells and dermal dendritic cells, which are professional antigen processing and presenting cells. It is well established that several dermatoses are associated with $\mathrm{T}$-cell mediated immune responses. In these pathological skin conditions, T-cells are activated by professional antigen presenting cells and dendritic cells are the most potent antigen presenting cells for both Thelper cells and T-cytotoxic cells. Therefore, it is plausible that dendritic cells are crucially involved in the pathogenesis of lymphoproliferative skin conditions characterized by the presence of a T-cell infiltrate. In this study, we examined the frequency and distribution of CD1a expressing cells and $\mathrm{CD}^{+}$ cells in both the dermal and epidermal compartment in a wide range of lymphoproliferative dermatoses with a T-lymphoid infiltrate. In the skin conditions investigated, the CD1a molecule was highly expressed in mycosis fungoides, T-cutaneous lymphoid hyperplasia, lymphomatoid papulosis and parapsoriasis, whereas few CD1a-positive cells were observed in cutaneous B-cell lymphomas. Our study demonstrates a distinct pattern of CD1a staining in the infiltrates of cutaneous lymphoproliferative disorders which may reflect different immunoregulatory events involving T-lymphocytes and CD1a-positive dermal and epidermal dendritic cells.
\end{abstract}

\section{Introduction}

The CD1 family comprises small to moderate sized molecules of $\beta_{2}$-microglobulin-associated, transmembrane glycoproteins. They are structurally related to the MHC-class I molecules but their genes are unlinked to the MHC locus and they do not have the extensive polymorphism of classical MHC encoded antigen presenting molecules $(1,2)$. In humans, the CD1 family has five members: CD1a, CD1b, CD1c, CD1d

Correspondence to: Professor Mauro Alaibac, Unit of Dermatology, University of Padua, Via C. Battisti 206, I-35128 Padova, Italy

E-mail: mauro.alaibac@unipd.it

Key words: Langerhans cells, cutaneous lymphomas, T-lymphocytes, B-lymphocytes, dendritic cells, CD1a and CD1e proteins. Among these, it has been proposed that two or perhaps three distinct groups of CD1 proteins can be discriminated on the basis of sequence homologies, sites of expression and function. Thus, CD1a, CD1b and CD1c are typically classified as group $1 \mathrm{CD} 1$ proteins, while the more divergent CD1d protein comprises group 2 (3). The CD1e protein is considered intermediate in terms of its homology to group 1 and group 2 CD1 proteins and its expression is confined exclusively to intracellular compartments of myeloid lineage cells. Thus, the CD1e protein is currently classified as a group 3 CD1 (4).

In contrast to MHC molecules, which present antigenic peptides for recognition by specific T cells, it has been demonstrated that CD1-presented antigens are predominantly or exclusively lipid in nature (5). In accordance with this capacity, the $\mathrm{CD} 1$ proteins are expressed primarily on antigen presenting cells (6). The skin immune system is characterized by the presence of two types of CD1 expressing cells: Langerhans cells and dermal dendritic cells, which are professional antigen processing and presenting cells; these cells are known to play pivotal roles during the induction phase of adaptive immune responses and were shown to express high levels of CD1a $(7,8)$.

It is well established that several dermatoses are associated with T-cell mediated immune responses (9-12). In these pathological skin conditions, T-cells are activated by professional antigen presenting cells and dendritic cells are the most potent antigen presenting cells for both T-helper cells and T-cytotoxic cells (13). Therefore, it is plausible that dendritic cells are crucially involved in the pathogenesis of lymphoproliferative skin conditions with a T-cell infiltrate. In this study, we examined the frequency and distribution of CD1a expressing cells and $\mathrm{CD}^{+}$cells in both the dermal and epidermal compartment in a wide range of B- and T-lymphoproliferative dermatoses characterized by the presence of a T-lymphoid infiltrate.

\section{Materials and methods}

The study included tissue samples of 31 cases of lymphoproliferative skin conditions (Table I). All tissue samples had been obtained for diagnostic purposes. Our immunohistological experiments included sections of both normal human skin from 5 different subjects and 15 cases of inflammatory skin conditions as control. Tissues were snap-frozen in liquid nitrogen and stored at $-80^{\circ} \mathrm{C}$. Detection of CD1a was per- 
Table I. Lymphoproliferative dermatoses included in our study: a negative immunohistochemically analysis of the antigens CD1 and CD3 is shown as -; positivity is scored as + (low), ++ (moderate) and +++ (strong).

Diagnosis Antigen Epidermis Derma

\section{Cutaneous B-cell}

lymphoma

Case 1
Case 2
Case 3
Case 4
Case 5
utaneous CD30+
Case 1

Case 1

Case 2

Case 3

$\begin{array}{lcc}\text { CD1a } & +++ & + \\ \text { CD3 } & - & +++ \\ \text { CD1a } & + & +++ \\ \text { CD3 } & - & +++ \\ \text { CD1a } & ++ & - \\ \text { CD3 } & - & ++ \\ \text { CD1a } & ++ & + \\ \text { CD3 } & - & + \\ \text { CD1a } & ++ & ++ \\ \text { CD3 } & - & +++\end{array}$

Mycosis fungoides

(patch/plaque stage)

\begin{tabular}{|c|c|c|c|}
\hline \multirow[t]{2}{*}{ Case 1} & CD1a & ++ & ++ \\
\hline & CD3 & + & +++ \\
\hline \multirow[t]{2}{*}{ Case 2} & CD1a & +++ & +++ \\
\hline & CD3 & +++ & +++ \\
\hline \multirow[t]{2}{*}{ Case 3} & CD1a & +++ & ++ \\
\hline & CD3 & +++ & ++ \\
\hline \multirow[t]{2}{*}{ Case 4} & CD1a & +++ & +++ \\
\hline & CD3 & - & +++ \\
\hline \multirow[t]{2}{*}{ Case 5} & CD1a & ++ & ++ \\
\hline & CD3 & ++ & +++ \\
\hline \multirow[t]{2}{*}{ Case 6} & CD1a & ++ & ++ \\
\hline & CD3 & + & +++ \\
\hline \multirow[t]{2}{*}{ Case 7} & CD1a & ++ & ++ \\
\hline & CD3 & ++ & +++ \\
\hline \multirow[t]{2}{*}{ Case 8} & CD1a & +++ & ++ \\
\hline & CD3 & + & +++ \\
\hline \multirow[t]{2}{*}{ Case 9} & CD1a & +++ & +++ \\
\hline & CD3 & ++ & +++ \\
\hline \multirow[t]{2}{*}{ Case 10} & CD1a & ++ & ++ \\
\hline & CD3 & + & ++ \\
\hline \multirow[t]{2}{*}{ Case 11} & CD1a & ++ & ++ \\
\hline & CD3 & ++ & +++ \\
\hline \multirow[t]{2}{*}{ Case 12} & CD1a & + & + \\
\hline & CD3 & + & +++ \\
\hline
\end{tabular}

CD1a
CD3
CD1a
CD3
CD1a
CD3

Table I. Continued.

\begin{tabular}{l} 
Diagnosis \\
\hline Lymphomatoid \\
papulosis \\
Case 1
\end{tabular}

\section{Case 1}

Case 2

$\begin{array}{cc} & \\ + & + \\ - & +++ \\ ++ & +++ \\ + & +++ \\ +++ & ++ \\ + & +++\end{array}$

\section{T-cutaneous lymphoid hyperplasia}

Case 1
Case 2
Case 3

Sezary syndrome

\begin{tabular}{llcc} 
Case 1 & CD1a & + & + \\
& CD3 & ++ & ++ \\
Case 2 & CD1a & + & + \\
& CD3 & - & +++ \\
\hline
\end{tabular}

formed on frozen sections from reactive and neoplastic skin conditions using an anti-CD1a monoclonal antibody (mAb, clone NA1/34; Dako). The following mAbs were also used in the study: CD3 (clone UCHT1; Dako, Glostrup, Denmark), CD4 (clone MT310; Dako), CD5 (clone DK23; Dako), CD7 (clone DK24; Dako), CD8 (clone DK25; Dako) and CD19 (clone HD37; Dako). Air-dried, acetone-fixed frozen sections were incubated overnight with the mAbs and, after washing, processed with a standard alkaline phosphatase anti-alkaline phosphatase (APAAP) technique. Rabbit anti-mouse Ig (Dako) was applied for $30 \mathrm{~min}$ and, after washing, the sections were incubated with APAAP-complex (Dako) for $30 \mathrm{~min}$. Naphtol-AS-MX phosphate along with Fast Red TR salt were used for the development of alkaline phosphatase. The endogenous alkaline phosphatase was blocked by adding levamisole to the substrate. Sections were counterstained for 5 min with Mayer's hematoxylin. Negative controls were performed by omitting the primary mAb on samples or consisted of replacement of the primary antibody with another irrelevant mAb of identical isotype. We evaluated 


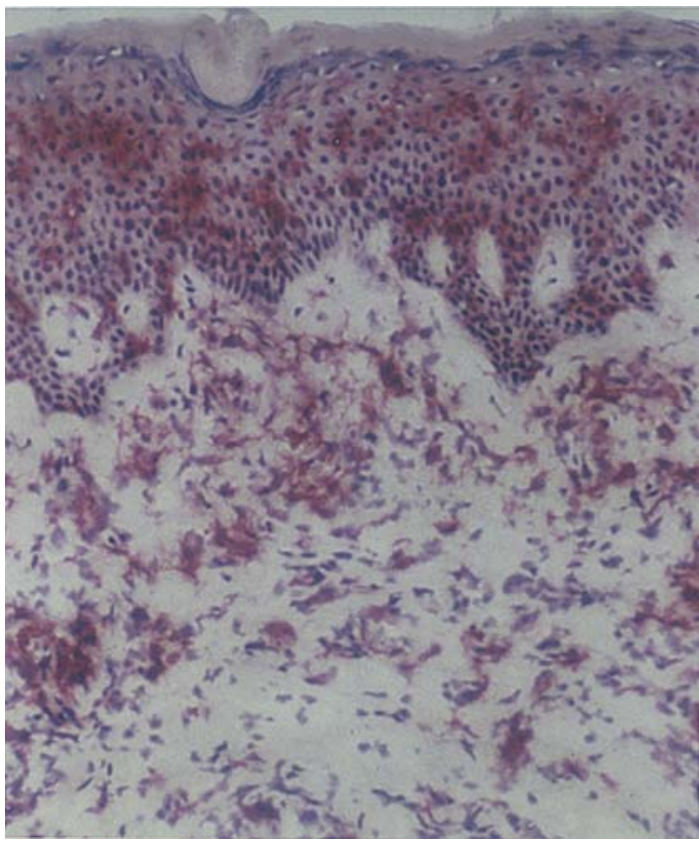

Figure 1. Representative immunostaining of a case of mycosis fungoides showing numerous $\mathrm{CD} \mathrm{a}^{+}$cells in both the epidermal and dermal compartment (APAAP, $x 40)$.

CD1a and CD3 reactivity according to the following grading system: -, absent; +, low; ++, moderate; +++, strong.

\section{Results}

On frozen sections of normal skin, CD1a-positive cells formed an evident reticule in epidermis and they were not generally noticed in the dermis. CD3-positive cells were present only in the perivasal dermal and the epidermal expression of the CD3 molecule was observed only in a few isolated lymphocytes.

In lymphoproliferative skin conditions, the CD1a molecule was highly expressed in the cases of patch/plaque-stage mycosis fungoides investigated in both the epidermal and dermal compartment (Fig. 1). In this condition, a dense CD3positive cell dermal infiltrate was present and it was in some cases associated with epidermotropism of CD3-positive cells. A strong dermal and epidermal expression of the CD1a molecule was also detected in T-cutaneous lymphoid hyperplasia, lymphomatoid papulosis and parapsoriasis. In these conditions, an abundant dermal cellular CD3-positive infiltrate was present, whereas epidermotropism of $\mathrm{CD}^{+}$cells was generally modest or absent. In the 5 cases of cutaneous B-cell lymphoma, we generally observed a strong dermal infiltrate of T-lymphocytes, but few CD1a ${ }^{+}$cells in both the dermal and epidermal compartment (Fig. 2). A similar situation was detected in one of the 3 cases of cutaneous $\mathrm{CD}^{+} 0^{+}$anaplastic large cell lymphoma included in the study, but not in the other 2 cases. A low expression of CD1a was also detected in the 2 cases of Sezary syndrome investigated. The results concerning the expression of the CD1a molecule in lymphoproliferative dermatoses are summarized in Table I.

We also investigated as control a small group of inflammatory skin conditions. In these cases, $\mathrm{CD} \mathrm{a}^{+}$dermal dendritic cells were densely distributed within the lymphoid infiltrate in

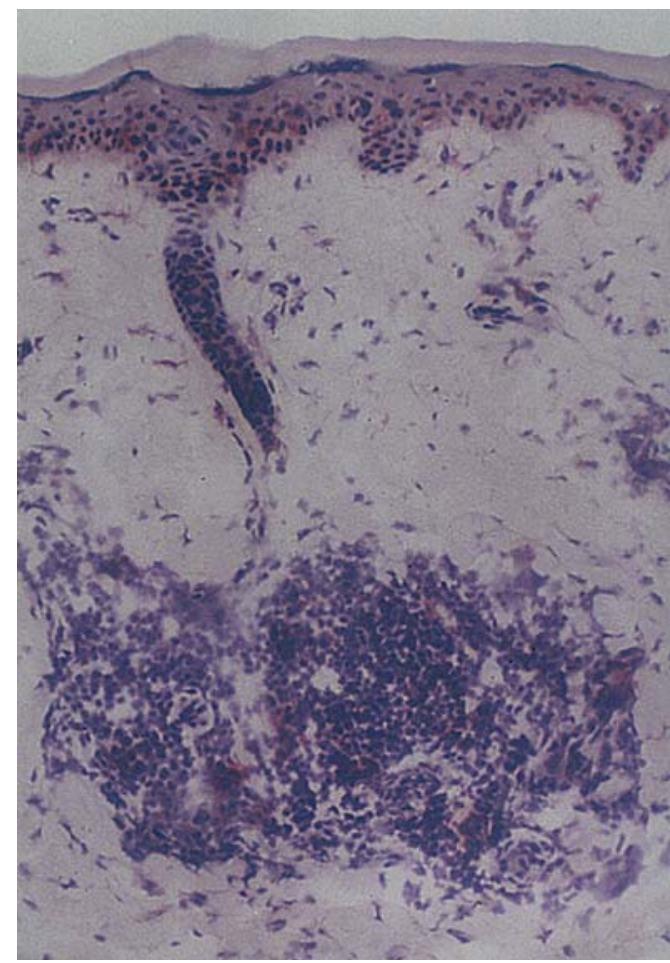

Figure 2. Representative immunostaining of a case of cutaneous B-cell lymphoma demonstrating only a few epidermal and dermal $\mathrm{CD} 1 \mathrm{a}^{+}$dendritic cells (APAAP, $\mathrm{x} 40$ ).

the affected dermis of contact dermatitis, psoriasis and lichen planus. A strong expression of CD1a was also observed in the epidermal compartment, although epidermotropism of $\mathrm{CD}^{+}$ cells was not generally observed.

\section{Discussion}

Mycosis fungoides is the most common T-cell cutaneous lymphoma and it generally shows a slow progressive clinical course. Histologically, mycosis fungoides is characterized by a dermal infiltrate of CD3-positive/CD4-positive cells associated with the epidermotropism of neoplastic cells (14). In our study, we demonstrate in patch/plaque-stage mycosis fungoides a strong correlation between the number of CD3-positive T-cells in the dermal compartment and the expression of the CD1a molecule in both the dermis and epidermis. This situation is in agreement with previous reports $(15,16)$ and very similar to T-cell mediated inflammatory dermatoses such as contact dermatitis (17). Mycosis fungoides, particularly in its early stages, is immunologically and phenotypically very close to contact dermatitis and often these two situations are difficult to discriminate. There is, thus, clinical and experimental evidence that correlates the development of mycosis fungoides with a situation of chronic inflammation derived from a reaction to continual antigen stimulation. This analogy with contact dermatitis supports the hypothesis that this cutaneous lymphoma could take origin from a neoplastic transformation of a T-helper cell clone involved in a cutaneous immunological response (18). Our data about the density of dendritic cells expressing the CD1a molecule and T-cells are in agreement with this immunopathological model. An original finding has been the observation that the density of epidermal CD1a- 
positive cells was not associated with the epidermotropism of CD3-positive cells, suggesting that epidermal Langerhans cells are equally operative in this situation, even if only a predominant dermal involvement is present.

In the two cases of Sezary syndrome investigated in our study, we found a low number of CD1a-positive dendritic cells in both the dermal and epidermal compartment. Sezary syndrome is an aggressive variant of cutaneous T-cell lymphoma with a poor prognosis if compared with mycosis fungoides. Our findings probably reflect the different clinical behaviour of these lymphoproliferative skin conditions.

Expression of the CD1a molecule in parapsoriasis was similar to that observed in mycosis fungoides. This cutaneous disorder is characterized by clinical and histological features analogous to early mycosis fungoides and is considered by some authors to be a pre-mycosis stage $(19,20)$. This similitude is probably indicative of a common immunopathological mechanism characterized also in this condition by chronic antigen stimulation, which determines T-cell proliferation with mycosis fungoides-like histological and immunophenotypical features. A similar situation concerning CD1a expression was observed in T-cutaneous lymphoid hyperplasia which has been proposed to be the benign end of a continuum of lymphoproliferative disorders with cutaneous T-cell lymphoma at its malignant extreme (21).

In cutaneous $\mathrm{CD} 30^{+}$anaplastic large cell lymphomas, in situ immunohistochemical analysis demonstrated, in 1 out of 3 cases, a low expression of the CD1a molecule in both the dermal and epidermal compartment and, however, the presence of a strong $\mathrm{CD}^{+}$infiltrate. This type of cutaneous lymphoma is characterized by clinical and histological differences from mycosis fungoides (22). The variable expression of the CD1a molecule in this cutaneous lymphoma suggests that, in this condition, an immunopathological mechanism different to that proposed for mycosis fungoides is involved. This hypothesis is consistent with the clinical course of cutaneous CD30+ anaplastic large cell lymphomas, characterized by spontaneous remissions and disease reactivation, whereas in mycosis fungoides the course is usually progressive $(23,24)$. It has been shown that T-cells expressing the CD30 molecule have a cytokine profile characterized by a high production of IL-10. Particularly, a marked expression of this cytokine has been found in nodal anaplastic large cell lymphomas, characterized by the proliferation of CD30-positive cells (25). IL-10 is shown to inhibit the CD1a molecule $(26,27)$ and it is possible that, in a reactivation phase of the disease, an increase in IL-10 secretion by $\mathrm{CD}-30^{+}$neoplastic cells may have determined a low expression of CD1a in one of the 3 cases of cutaneous $\mathrm{CD}^{+} 0^{+}$anaplastic large cell lymphomas. However, numerous $\mathrm{CD} 1 \mathrm{a}^{+}$cells were observed in the lesions of the other two patients and also in lymphomatoid papulosis, which is an indolent form of cutaneous CD30-positive T-cell lymphoma. This suggests that the presence or absence of CD1a in these conditions may reflect a different stage of disease progression and/or biological behaviour.

In cutaneous B-cell lymphomas, the infiltrate frequently showed a moderate expression of CD1a which was generally confined to T-cell-rich areas as previously reported (28). However, the number of CD1a-positive cells only in one case correlated with the expression of $\mathrm{CD}^{+}$cells. These findings suggest that the recruitment of CD1a cells in T-cell-rich areas is probably hampered by neoplastic B-cell proliferation. It is plausible that neoplastic B-lymphocytes produce cytokines inhibiting the recruitment of $\mathrm{CD} 1 \mathrm{a}^{+}$dendritic cells in the skin and, consequently, the local response by T-cell mediated antitumor activity.

In conclusion, we have investigated the expression of the CD1a molecule in a group of well-characterised cutaneous lymphoproliferative conditions. The relationship between expression of CD1a protein and the cytokinic milieu may help to clarify the immunopathological mechanisms which are operative in these disorders.

\section{References}

1. Calabi F and Milstein C: The molecular biology of CD1. Semin Immunol 12: 503-509, 2000.

2. Porcelli SA and Modlin RL: The CD1 system: antigen-presenting molecules for T cell recognition of lipids and glycolipids. Annu Rev Immunol 17: 297-329, 1999.

3. Calabi F, Jarvis JM, Martin L and Milstein C: Two classes of CD1 genes. Eur J Immunol 19: 285-292, 1989.

4. Angenieux C, Salamero J, Fricker D, et al: Characterization of CD1e, a third type of CD1 molecule expressed in dendritic cells. J Biol Chem 275: 37757-37764, 2000.

5. Beckman EM, Porcelli SA, Morita CT, Behar SM, Furlong ST and Brenner MB: Recognition of a lipid antigen by CD1restricted $+\mathrm{T}$ cells. Nature 372: 691-694, 1994.

6. Richters CD, Hoekstra MJ, van Baare J, Du Pont JS, Hoefsmit EC and Kamperdijk EW: Migratory properties and functional capacities of human skin dendritic cells. Br J Dermatol 133: 721-727, 1995.

7. Hart DN: Dendritic cells: unique leukocyte populations which control the primary immune response. Blood 90: 3245-3287, 1997.

8. Hart DN, Dark GJ, Dekker JW, Fearnley DB, et al: Dendritic cell surface molecules. A proliferating field. Adv Exp Med Biol 417: 439-442, 1997

9. Deguchi M, Ohtani H, Sato E, Naito Y, Natura H, Aiba S and Tagami H: Proliferative activity of CD8(+) T cells as an important clue to analyze T cell-mediated inflammatory dermatoses. Arch Dermatol Res 293: 442-447, 2001.

10. Enk AH and Katz SI: Contact sensitivity as a model for T-cell activation in skin. J Invest Dermatol 105: S80-S83, 1995.

11. Hirota J, Osaki T and Tatemoto Y: Immunohistochemical staining of infiltrates in oral lichen planus. Pathol Res Pract 186: 625-632, 1990.

12. Vermeer $\mathrm{MH}$, van Doorn $\mathrm{R}$, Dukers $\mathrm{D}$, et al: $\mathrm{CD}^{+} \mathrm{T}$ cells in cutaneous T-cell lymphoma: expression of cytotoxic proteins, Fas ligand and killing inhibitory receptors and their relationship with clinical behaviour. J Clin Oncol 19: 4322-4329, 2001

13. Banchereau J and Steinman RM: Dendritic cells and the control of immunity. Nature 392: 245-252, 1998.

14. Burg G, Dummer R, Haeffner A, et al: From inflammation to neoplasia: mycosis fungoides evolves from reactive inflammatory conditions (lymphoid infiltrates) transforming into neoplastic plaques and tumors. Arch Dermatol 137: 949-952, 2001.

15. Lüftl M, Feng A, Licha E and Schuler G: Dendritic cells and apoptosis in mycosis fungoides. Br J Dermatol 147: 1171-1176, 2002.

16. Goteri G, Filosa A, Mannello B, Stramazzotti D, Rupoli S, Leoni P and Fabris G: Density of neoplastic lymphoid infiltrate, $\mathrm{CD}^{+} \mathrm{T}$ cells and $\mathrm{CD} 1 \mathrm{a}+$ dendritic cells in mycosis fungoides. $\mathbf{J}$ Clin Pathol 56: 453-459, 2003.

17. Deguchi M, Aiba S, Ohtani H, Nagura $H$ and Tagami $H$ : Comparison of the distribution and numbers of antigenpresenting cells among T-lymphocyte-mediated dermatoses. CD1a+, factor XIIIa+ and CD68+ cells in eczematous dermatitis, psoriasis, lichen planus and graft-versus-host disease. Arch Dermatol Res 294: 297-302, 2002.

18. Hansen ER: Immunoregulatory events in the skin of patients with cutaneous T-cell lymphoma. Arch Dermatol 132: 554-561, 1996.

19. Landa NG, Zelickson BD, Peters MS, Mulle SA and Pittelkow MR: Lymphoma versus pseudolymphoma of the skin: gene rearrangement study of 21 cases with clinicopathologic correlation. J Am Acad Dermatol 29: 945-953, 1993. 
20. Cerroni L and Goteri G: Differential diagnosis between cutaneous lymphoma and pseudolymphoma. Anal Quant Cytol Histol 25: 191-198, 2003.

21. Nihal M, Mikkola D, Horvath N, et al: Cutaneous lymphoid hyperplasia: a lymphoproliferative continuum with lymphomatous potential. Hum Pathol 34: 617-622, 2003.

22. Drews R, Samel A and Kadin ME: Lymphomatoid papulosis and anaplastic large cell lymphomas of the skin. Semin Cutan Med Surg 19: 109-117, 2000.

23. Dummer R, Hess-Schmid M and Burg G: Cutaneous T-cell lymphomas: prognosis and quality-of-life issues. Clin Lymphoma 1 (suppl 1): S521-S525, 2000.

24. Willemze R and Meijer CJ: Primary cutaneous CD30-positive lymphoproliferative disorders. Hematol Oncol North Am 17: 1319-1332, 2003.
25. Boulland ML, Meignin V, Leroy-Viard K, et al: Interleukin-10 expression in T/natural killer-cell lymphomas: association with anaplastic large cell lymphomas and nasal natural killer-cell lymphomas. Am J Pathol 153: 1229-1237, 1998.

26. De Kleer IM, Kamphuis SM, Rijkers GT, et al: The spontaneous remission of juvenile idiopathic arthritis is characterized by $\mathrm{CD} 30+\mathrm{T}$ cells directed to human heat-shock protein 60 capable of producing the regulatory cytokine interleukin-10. Arthritis Rheum 48: 2001-2010, 2003.

27. Gerli R, Pitzalis C, Bistoni O, Falini B, Costantini V, Russano A and Lunardi $\mathrm{C}$ : $\mathrm{CD} 30+\mathrm{T}$ cells in rheumatoid synovitis: mechanisms of recruitment and functional role. J Immunol 164: 4399-4407, 2000.

28. Schmuth M, Sidoroff A, Danner B, Topar G and Sepp NT: Reduced number of CD1a+ cells in cutaneous B-cell lymphoma. Am J Clin Pathol 116: 72-78, 2001. 